\title{
Development and Verification of Control System for Heat Recovery Ground Source Heat Pump System
}

\author{
Takao Katsura, PhD \\ Katsunori Nagano, PhD
}

\author{
Yutaka Shoji Yoshiki Miyashita \\ Yasushi Nakamura, PhD
}

\begin{abstract}
An operation method and control system for heat recovery ground source heat pump (HR-GSHP) systems have been developed. By applying the operation method and control system, the heating and cooling output from the respective GSHP units can be controlled according to the operational condition. This maximizes the energy saving effect by operating the GSHP units without excess temperature change of the heat carrier fluid. In this paper, the outlines of HR-GSHP system and the importance of control system for the HR-GSHP systems were firstly explained. Next, the control system's configuration and the control methodology were explained. In addition, the operation of a HR-GSHP system with the control system, in which the control methodology had been installed, was verified by using the field test apparatus. As the result, it was confirmed that the above control methodologies were applicable.
\end{abstract}

\section{NTRODUCTI ON}

Ground source heat pump (GSHP) systems have gained attention in Japan since the ground thermal energy was defined as one of the renewable energies in 2009. In a period before and behind it, the research works to promote the installation of GSHP systems especially in the moderate climate region such as Tokyo were carried out. As the representative examples, developments of design method and operation system for hybrid GSHP systems combined with the cooling tower are mentioned (Katsura et.al, 2011, Katsura et.al, 2014). However, the number of GSHP systems installed in Japan is still smaller than other countries due to the higher installation cost for ground heat exchangers (GHEXs). Especially, there are few examples of large GSHP systems with a total heating or cooling capacity of more than several hundred $\mathrm{kW}$.

The advantages of heat recovery GSHP (HR-GSHP) systems could potentially promote the installation of large GSHP systems. The HR-GSHP system has several types of GSHP units for different uses connected to the GHEXs in order to yield two types of heat recovery effects. The first type of heat recovery is the direct heat recovery effect obtained by operating several types of GSHP units, such as cooling and hot water supply, at the same time; this effect is the same as that of the conventional heat recovery heat pump system with the double-bundle condenser (ASHRAE handbook, 2008). The other type of heat recovery is the indirect heat recovery effect that utilizes underground thermal storage and is obtained by short-term alternate operation of several types of GSHP units. By utilizing these two heat recoveries, the HR-GSHP system can yield both of energy saving and drastic reduction of the total GHEX length. Therefore, the HRGSHP system has a large potential for saving energy in large-scale complex buildings and industrial plants, which require both heating and cooling at the same time. The authors focused attention on this point and the design method for HRGSHP systems applying the optimization method was established (Katsura et.al, 2017).

Takao Katsura (katsura@eng.hokudai.ac.jp) is an associate professor, Graduate School of Engineering, Hokkaido University. 
In this paper, the control system for HR-GSHP systems is established. The HR-GSHP system has the GSHP units with the larger capacity compared to the total length of GHEXs because the direct heat recovery effect is expected. Thus, if the GSHP units operate with the maximum capacity under a situation where the direct heat recovery effect does not occur, the heat extraction or injection from GHEXs is not enough. Then, the temperature of heat carrier fluid decreases or increases excessively and the HR-GSHP system cannot be operated. Therefore, as shown in Figure 1 it is important to control the heat extraction or injection from the GSHP units when the multiple GSHP units are not operating for heating and cooling simultaneously. There are several research works related to the capacity control of GSHP units (Gao et.al, 2015) and the flow rate control of circulation pumps (Katsura et.al, 2011, Edward et.al, 2015) but no research works in which the capacity of GSHP units is controlled to prevent the excess variation of heat carrier fluid in the primary side of GSHP system. The authors firstly explain the outlines of control system. Also, the results of a verification of control operation using a field test apparatus are reported.

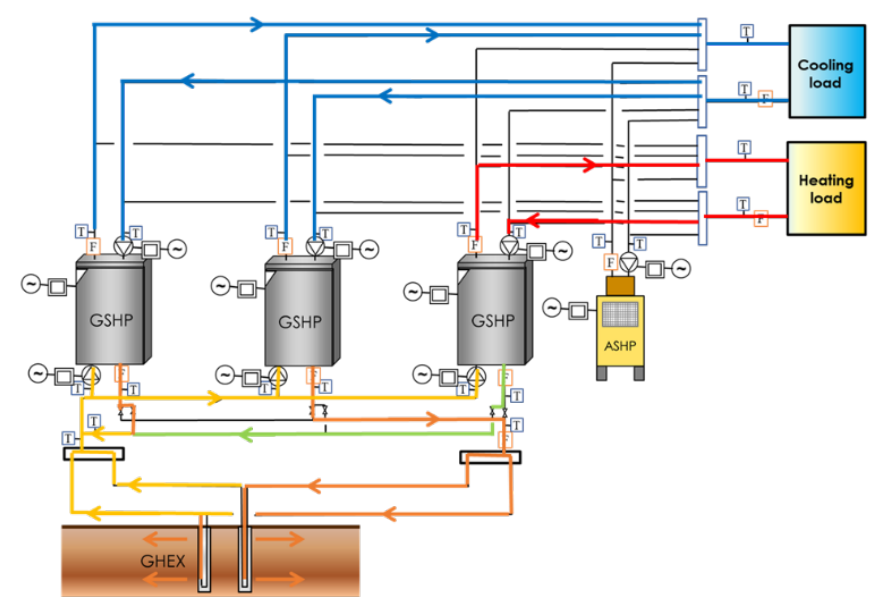

(a) Simultaneous both side operation for heating and cooling

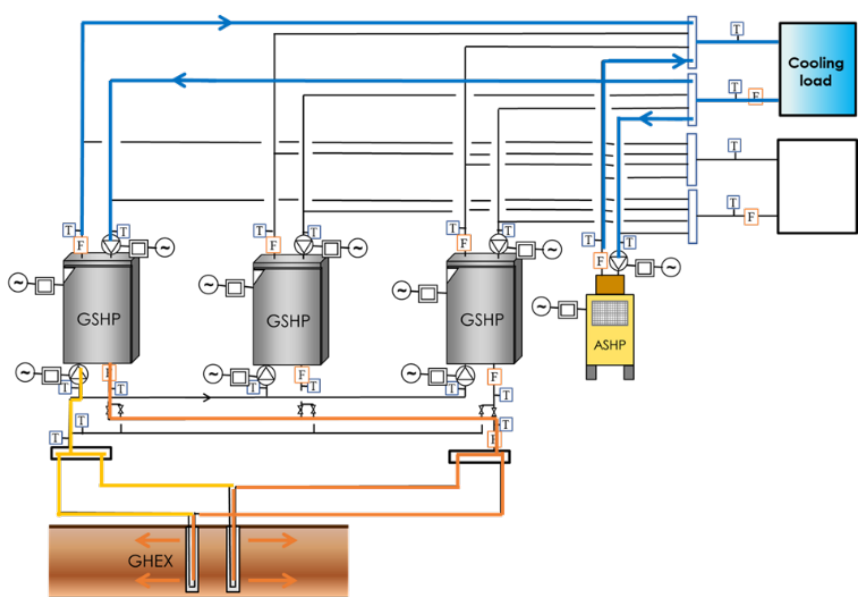

(b) Single side operation

Figure 1 Changing HR-GSHP system operation

\section{OUTLI NES OF THE HR-GSHP SYSTEM AND THE CONTROL SYSTEM}

\section{Outline of HR-GSHP systems}

Figure 1 shows a schematic diagram of HR-GSHP system, which is the control target. The HR-GSHP system has several types of GSHP units for different uses and the GSHP units are connected to the GHEXs. In the HR-GSHP system, the auxiliary heat source units such as the air source heat pump (ASHP) units, the absorption hot/cold water generators are equipped. In addition, the software and the PLC are installed to control the HR-GSHP system.

\section{Control Method of HR-GSHP Systems}

Figure 3 shows the flow chart of the control system for HR-GSHP systems. The PLC sends measurement data to the software, which carries out a simulation and determine the control parameters. The determined control parameters are sent to the PLC, which control the HR-GSHP system.

First, as shown in Figure 2(b), the authors introduce the control method in the case where the GSHP units are operated for either heating or cooling (Single side operation). In the case of Figure 2(b), The direct heat recovery effect cannot be expected; thus, the maximum output from GSHP units $\left(Q_{g 2 h \max }, Q_{g 2 c m a x}\right)$ in which the HR-GSHP system can operate continuously long term is determined with the software. 


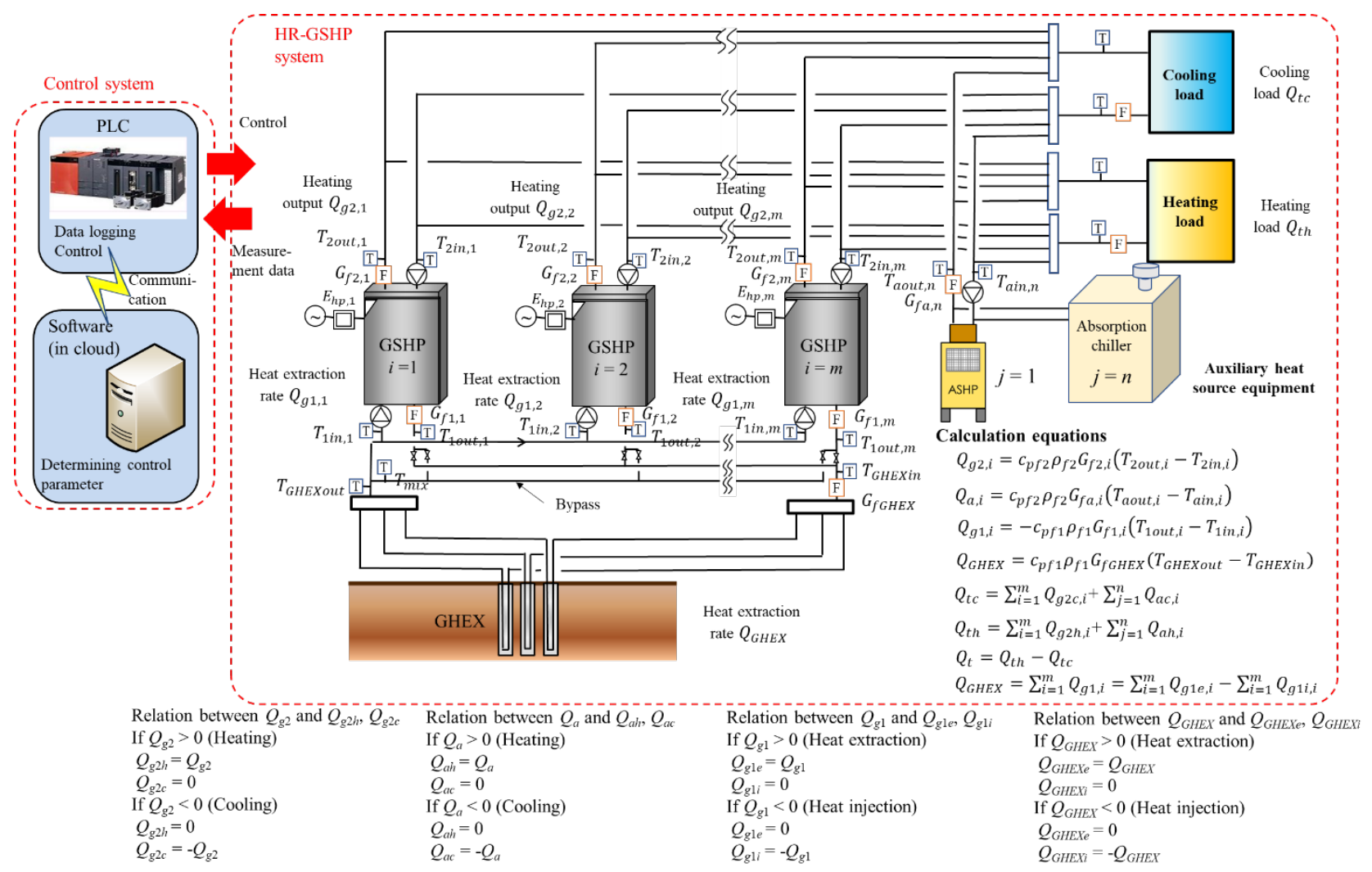

Figure 2 Schematic diagram of HR-GSHP system

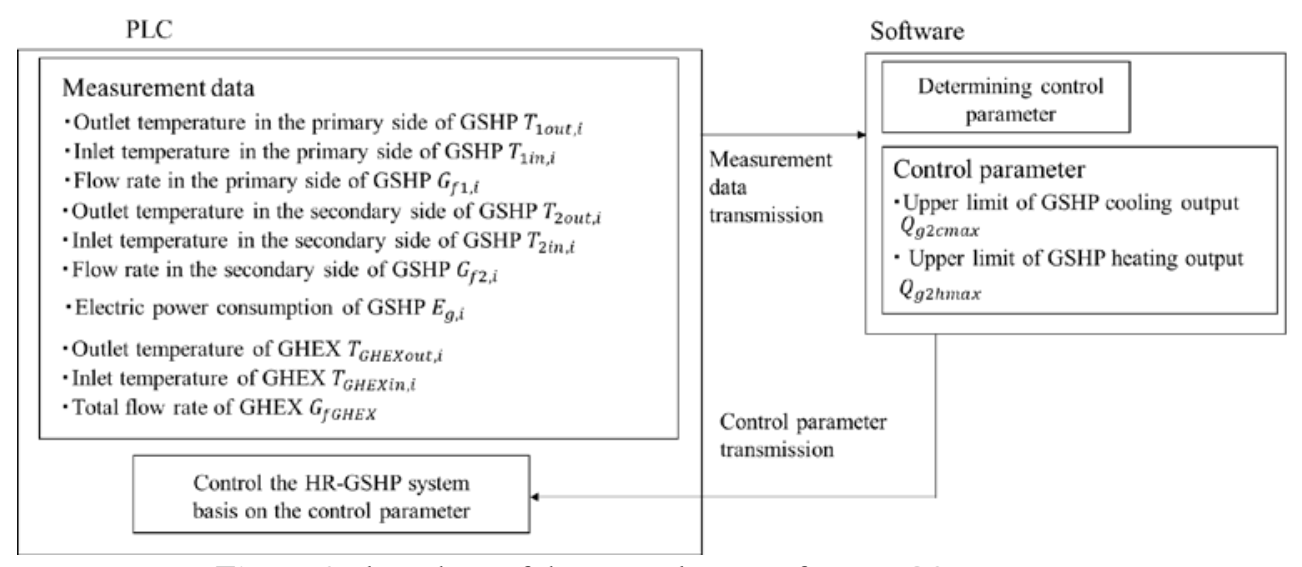

Figure 3 Flow chart of the control system for HR-GSHP system

Figure 4 shows the determination flow of $Q_{g 2 h \max }, Q_{g 2 c \max }$. Before determining $Q_{g 2 h \max }, Q_{g 2 c \max }$, the software estimates the apparent effective thermal conductivity of the ground by using the method introduce in the previous paper (Katsura et.al, 2014), the hourly load, and the heat pump coefficient of performance (COP), which are important parameters to carry out simulation. Subsequently, the simulation of HR-GSHP system are carried out and the temperature variation of heat carrier fluid considering the indirect heat recovery effect is predicted. Then, the simulation is repeated by changing $Q_{g 2 h \max }, Q_{g 2 c \max }$ and $Q_{g 2 h \max }, Q_{g 2 c \max }$ are determined in the condition that the temperature of heat carrier fluid is in the range of maximum and minimum set temperatures. Finally, the control parameters $Q_{g 2 h \max }, Q_{g 2 \text { cmax }}$ are sent to the PLC. The process shown in Figure 4 is generally conducted every week (However, the period can be changed). 


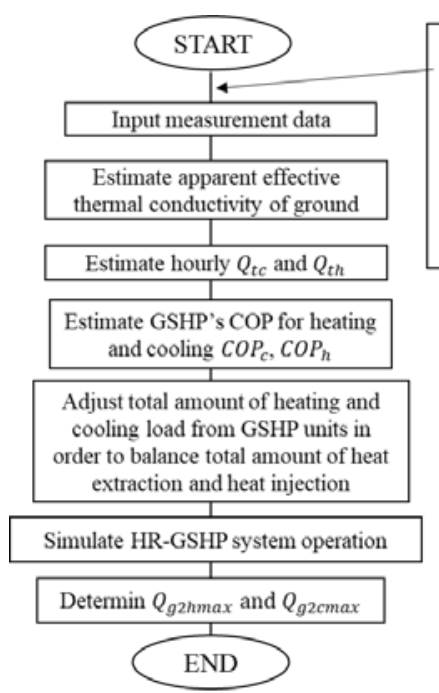

Figure 4 Flow chart for determining $Q_{g 2 h \max }, Q_{g 2 \text { cmax }}$
In the HR-GSHP system, the output from the GSHP units must be controlled depending on the determined $Q_{g 2 h \max }, Q_{g 2 \text { cmax }}$, and the auxiliary heat source units should be operated. Therefore, the authors introduce the base load control that can control the output from the GSHP units. The base load control keeps the output from the GSHP unit constant by adjusting the flow rate of cold/hot water from the heat source units in the HR-GSHP system that has two or more heat source units. Figure 5 shows the flow chart of base load control. In the HR-GSHP system with multiple heat source units, the secondary return temperature becomes the same; thus, the load is depending on the flow rate of each heat source unit. Therefore, the flow rate of each heat source unit is changed to distribute the load.

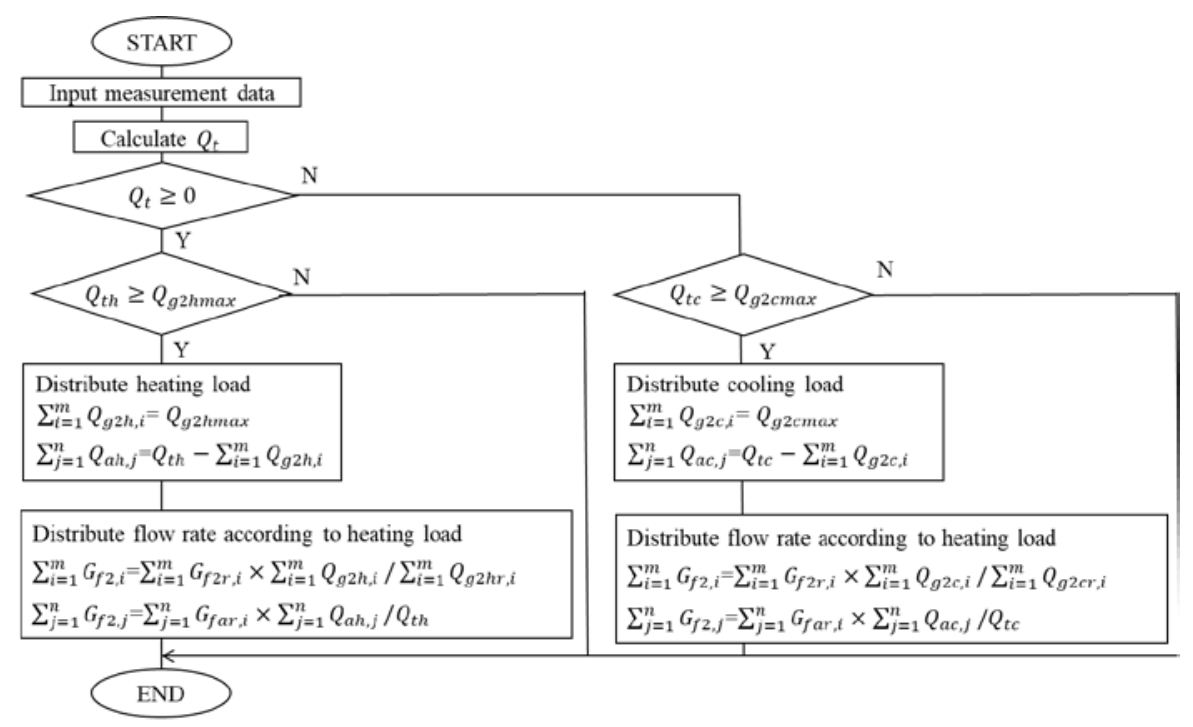

Figure 5 Flow chart of base load control

Next, as shown in Figure 2(a), the authors explain the control method in the case where the multiple GSHP units are simultaneously operated for both of heating and cooling (Both side operation). When the multiple GSHP units for heating and cooling are operated simultaneously, the maximum output $Q_{g 2 h p l c}$ and $Q_{g 2 c p l c}$ that considers simultaneous operation is calculated with the PLC as shown in Figure 6. Whether $Q_{g 2 h p l c}$ (or $Q_{g 2 c p l c}$ ) exceed $Q_{\text {g2hmax }}$ (or $Q_{\text {g2cmax }}$ ) is determined, and the output from the GSHP units is increased based on the result.

When the multiple GSHP units for heating and cooling are simultaneously operated, the total flow rate of the GSHP units might exceed the maximum flow rate of the GHEXs. To avoid such situation, the bypass system is installed in the primary side of the HR-GSHP system, as shown in Figure 2. In order to maximize the direct heat recovery effect, the flow rate in the bypass is adjusted so that $T_{\text {mix }}=T_{\text {GHEXout }}$. Then, the residual flow is sent to the GHEX. Here, the flow from each heat pump is adjusted indipendentely by controlling the revolution speed of circulation pump. And the revolution speed is controlled by adjusting the temperature difference between inlet and outlet of heat pump, which are $T_{1 \text { in }, i}$ and $T_{1 o u t, i}$ in Figure 2. 


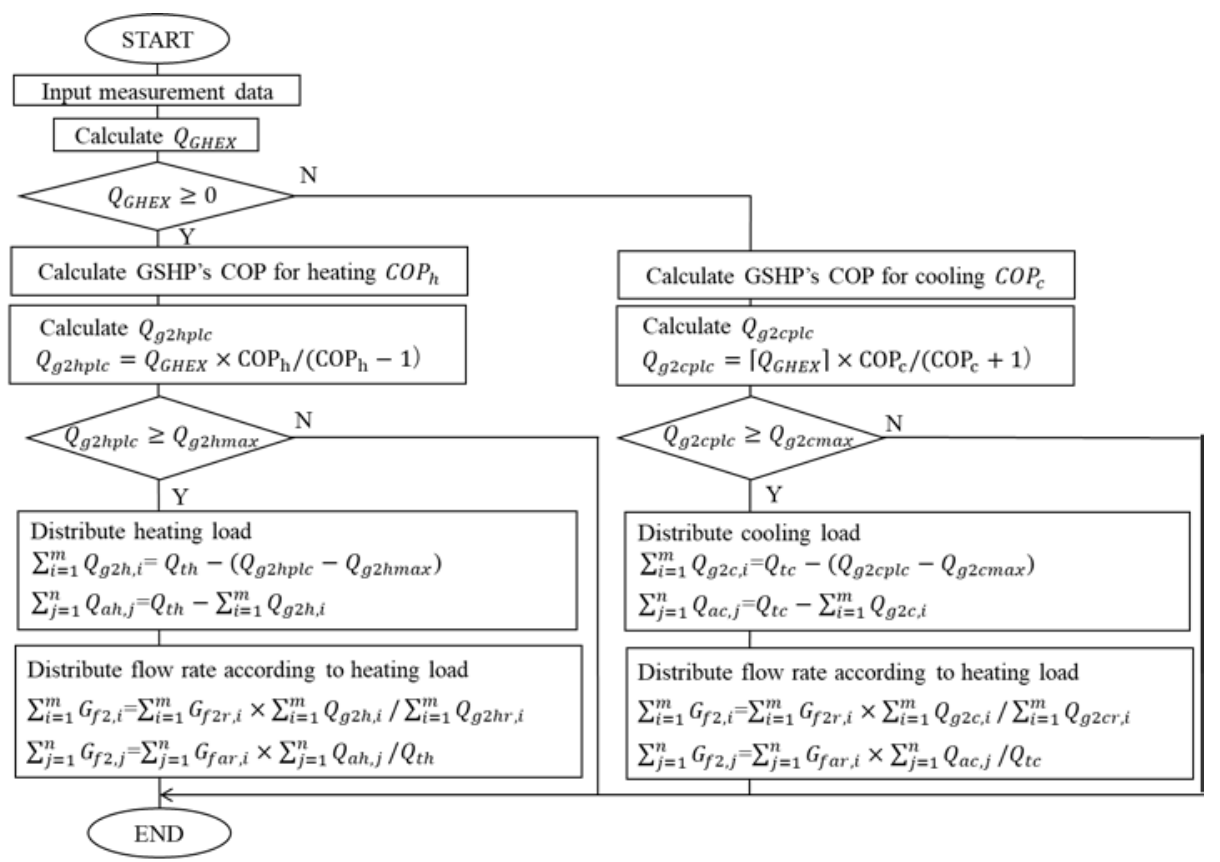

Figure 6 Flow chart of output control from GSHP units during simultaneous operation of multiple GSHP units

\section{VERI FI CATI ON OF CONTROL SYSTEM I N THE FIELD TEST}

\section{Outlines of Field Test Apparatus}

In order to verify the control system, the experiment apparatus for the HR- GSHP system has been constructed in the field of Hokkaido University since 2016. Figure 7 shows the diagram of the field test apparatus. The field test apparatus consists of the GHEXs, the multiple GSHP units, the ASHP units as the auxiliary heat source units. The field test apparatus can cover the cooling and heating loads in the range of $0 \sim 30 \mathrm{~kW}$ by using the load imitation tank. The feature of the test apparatus is that the capacity of each GSHP unit is small but multiple GSHP units are installed. In addition, it is possible to give the excessive load conditions that would be difficult to execute in the real building. The PLC in the field test apparatus can communicate with the software in cloud and control the HR-GSHP system. The software can determine the control parameters $Q_{g 2 \text { hmax }}$, $Q_{\text {g2 max }}$ and send them to the PLC.

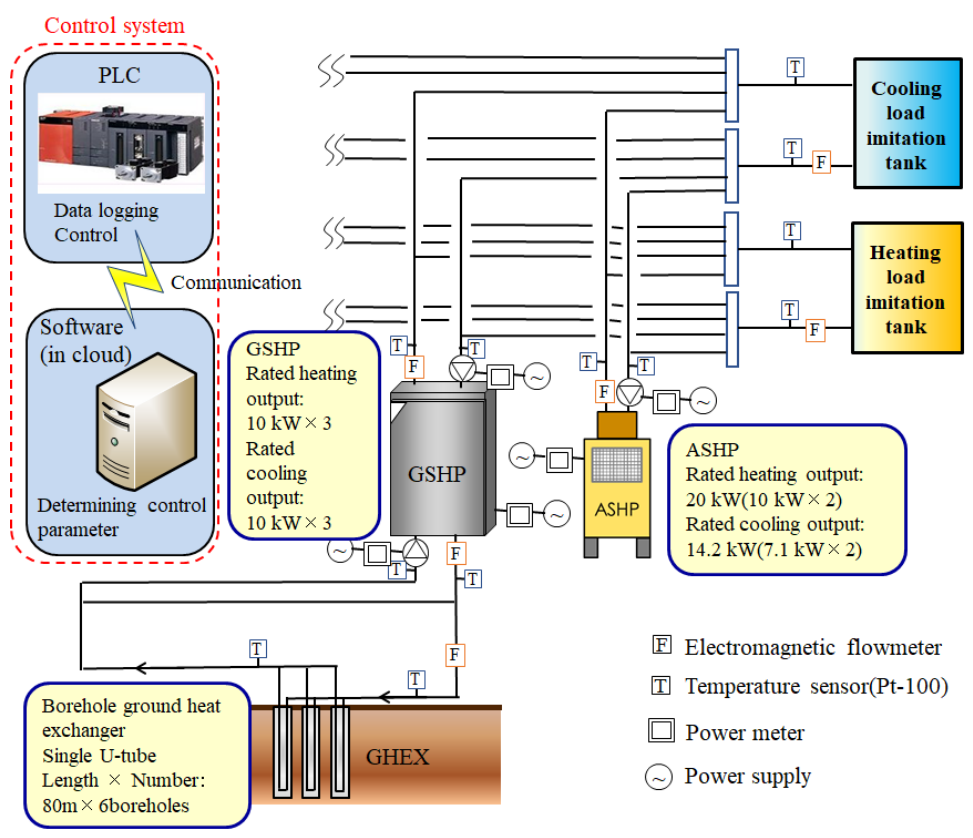

Figure 7 Diagram of the field experiment apparatus

\section{Verification of Control System}

The developed control system was verified by using the field test apparatus. The field test carried out on July 
2017. Table 1 shows the test conditions for the control system.

Table 1 Test conditions for control system

\begin{tabular}{|c|l|c|c|c|c|c|c}
\hline & Verified control & $Q_{t h}[\mathrm{~kW}]$ & $Q_{t c}[\mathrm{~kW}]$ & $Q_{g 2 h}[\mathrm{~kW}]$ & $Q_{g 2 c}[\mathrm{~kW}]$ & $Q_{a h}[\mathrm{~kW}]$ & $Q_{c h}[\mathrm{~kW}]$ \\
\hline CASE1 & Base load control & 0.0 & 11.1 & 0.0 & 4.0 & 0.0 & 7.1 \\
\hline CASE2 & $\begin{array}{l}\text { Output control from GSHP units during } \\
\text { simultaneous operation }\end{array}$ & 16.0 & 10.0 & 16.0 & 10.0 & 0.0 & 0.0 \\
\hline CASE3 & $\begin{array}{l}\text { Output control from GSHP units during } \\
\text { simultaneous operation + Base load control }\end{array}$ & 10.0 & 16.0 & 10.0 & 10.0 & 0.0 & 6.0 \\
\hline
\end{tabular}

First, the values of $Q_{g 2 h \max }, Q_{g 2 \text { cmax }}$ were calculated as $4 \mathrm{~kW}$ by using the software and given as the conditions for CASE1 to CASE3. In CASE1, the base load control was verified, the cooling load of $11 \mathrm{~kW}$ was given as the imitation load. Based on $Q_{g 2 c \max }=4 \mathrm{~kW}$, the control that retains the GSHP unit's cooling output as $4 \mathrm{~kW}$ and yields the ASHP unit's cooling output as $7 \mathrm{~kW}$ was verified. In CASE2, the output control from GSHP units during simultaneous operation, the cooling load of $10 \mathrm{~kW}$ and heating load of $16 \mathrm{~kW}$ were given as the imitation loads. And the simultaneous operation of the multiple GSHP units for heating and cooling in the HR-GSHP system was performed. However, in CASE2, the ASHP unit is not used because it was $Q_{G H E X}>0$ and $Q_{g 2 h p l c}<Q_{g 2 h m a x}$ in the flow shown in Figure 6. Next, in CASE3, both of the base load control and the output control was verified; the cooling load of 16 $\mathrm{kW}$ and heating load of $10 \mathrm{~kW}$ were given as the imitation load and the simultaneous operation of the multiple GSHP units for heating and cooling was performed as well as in CASE2. However, in CASE3, it becomes $Q_{G H E X}<0$ and $Q_{\text {g2hplc }} \geq Q_{g 2 h \max }$ in the flow shown in Figure 6; thus, the output from the GSHP unit for cooling is controlled, and the remaining cooling load should be covered by the ASHP unit. In other words, in CASE3, the control that provides the simultaneous operation of the multiple GSHP units and retains the GSHP unit's cooling output was verified.

As the result of CASE1, Figure 8 shows the variations of flow rate of the cold water from the GSHP unit and the ASHP, and Figure 9 shows the variations of cooling output from the GSHP unit and ASHP unit. Figure 8 shows that the flow rate of the cold water from the GSHP unit was kept at $10 \mathrm{~L} / \mathrm{min}$ and Figure 9 shows that the cooling output from the GSHP unit was kept at $4 \mathrm{~kW}$. These results indicated that the flow rate control was occurring, and the cooling output from GSHP (Light blue curve in Figure 9) was controlled according to the maximum output $Q_{g 2 h m a x}$. The cooling output from ASHP (Light green curve in Figure 9) was approximately $6 \mathrm{~kW}$, which was slightly below 7.1 $\mathrm{kW}$, but the load distribution was generally according to the control.

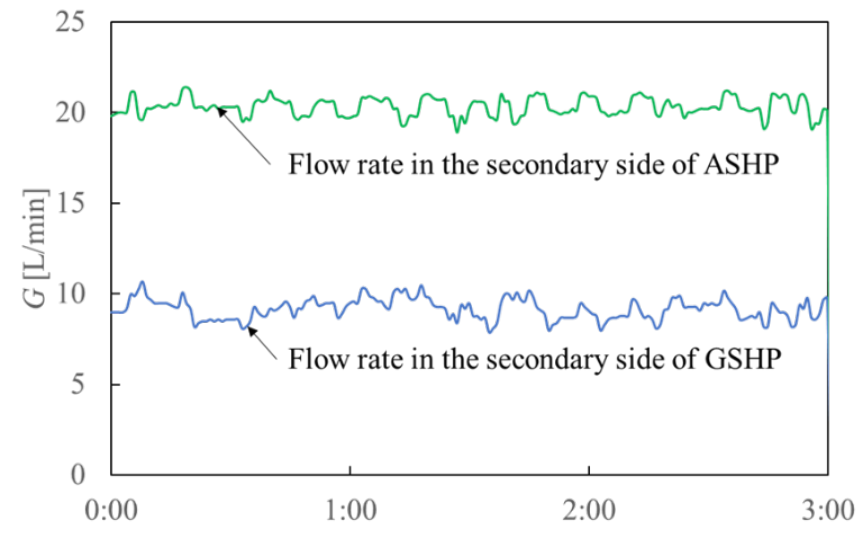

Figure 8 Variations of flow rate from GSHP unit and ASHP unit (CASE1)

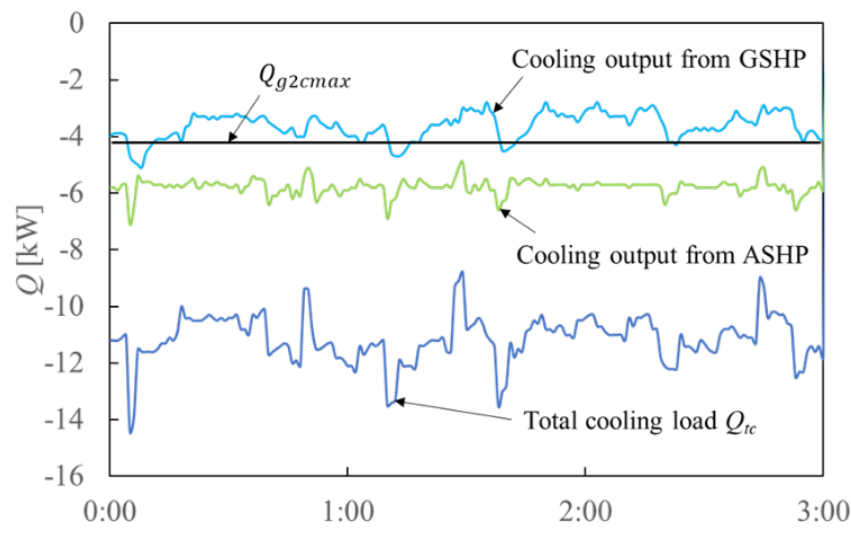

Figure 9 Variations of cooling output from GSHP unit and ASHP unit (CASE1) 
Next, as the result of CASE2, Figure 10 shows the variations of heat extraction/injection rate from the GSHP unit and the GHEXs. Figure 10 also shows the variations of temperatures $T_{\text {GHEXout }}$ (Red curve) and $T_{\text {mix }}$ (Right red curve), which are indicated in Figure 1. In addition, Figure 11 shows the variations of heating and cooling output from the GSHP units. Figure 10 indicated that it was almost $T_{m i x}=T_{G H E X o u t}$. In addition, it was confirmed that the heat extraction and injection from the multiple heat pump units were cancelled each other with the bypass and the only excess heat extraction was exchanged in the ground. In addition, the heating (Red curve) and cooling output (Light blue curve) from the GSHP units became larger than the values of $Q_{g 2 h \max }, Q_{g 2 c m a x}$ when the simultaneous operation of the multiple GSHP units was performed.

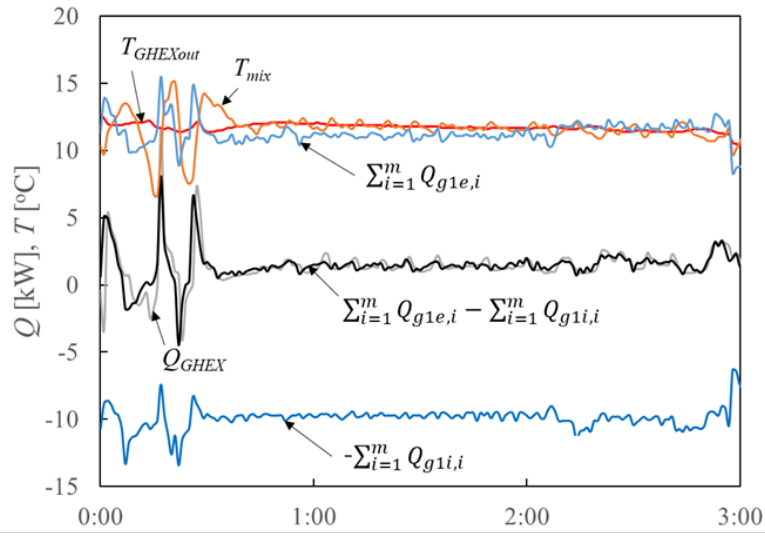

Figure 10 Variations of heat extraction/injection rate and temperatures (CASE2)

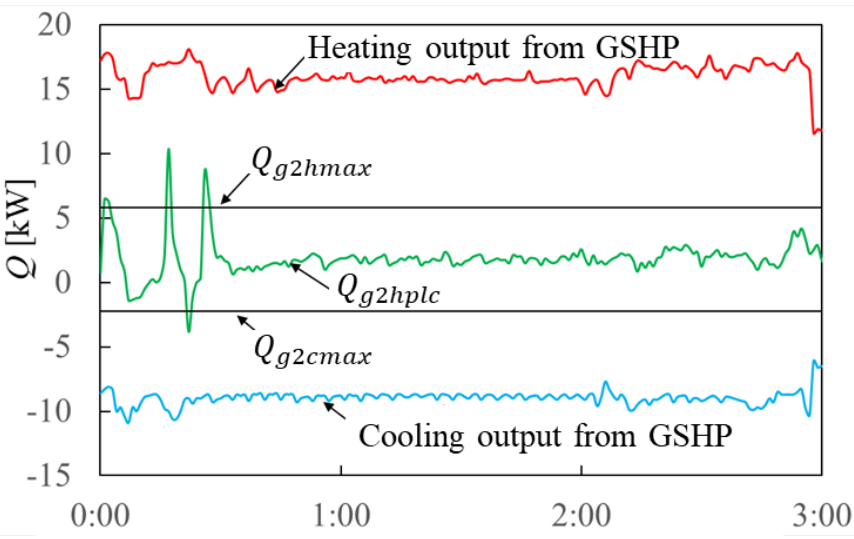

Figure 11 Variations of heating and cooling output from GSHP units (CASE2)

Furthermore, as a result of CASE3, Figure 12 shows the variations of heat extraction/injection rate and temperatures and Figure 13 shows the variations of heating and cooling output from the GSHP units and the ASHP unit. Figure 13 shows it was mostly $T_{\text {mix }}=T_{\text {GHEXout }}$ as well as in CASE2. Then, the heat extraction and injection from the multiple heat pump units were cancelled each other with the bypass, and the direct heat recovery effect was confirmed. In addition, the output from the GSHP unit for cooling was controlled, and the ASHP unit was operated as the auxiliary heat source unit. The cooling output from the GSHP unit (Light blue curve in Figure 13) and the ASHP unit (Light greem curve in Figure 13) were kept as $10 \mathrm{~kW}$ and $6 \mathrm{~kW}$, respectively. This result indicated the cooling outputs were properly distributed with the control system.

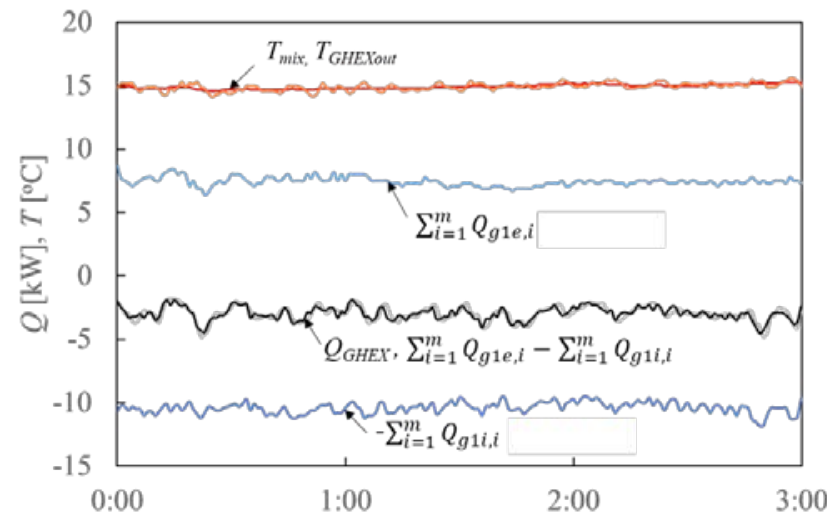

Figure 12 Variations of heat extraction/injection rate and temperatures (CASE3)

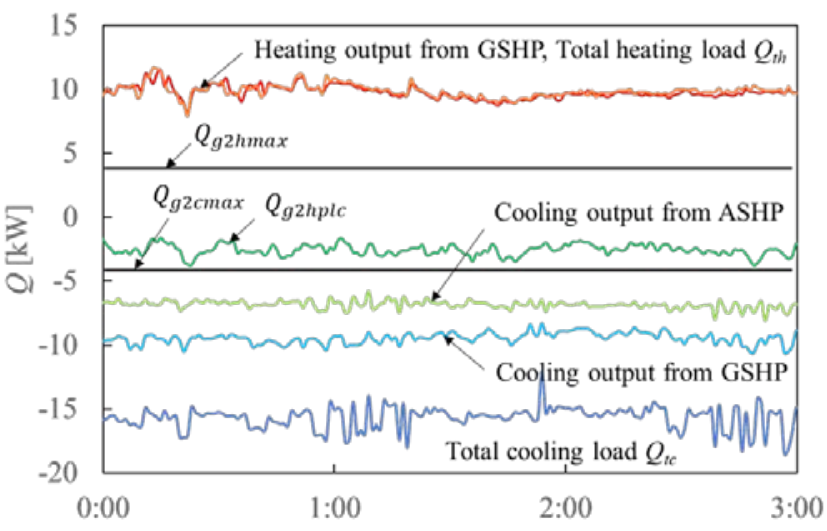

Figure 13 Variations of heating and cooling output from GSHP units and ASHP unit 


\section{CONCLUSION}

1) The control system for HR-GSHP systems, which consisted of a PLC and software, was developed. The control methodology has the following features:

- A method for determining the maximum allowable output from the GSHP units in case where the GSHP units are operated for either heating or cooling.

- The control method limits the output from the GSHP units and operates the auxiliary heat source unit so that the maximum allowable output is not exceeded.

- The control method of output from the GSHP unit during simultaneous operation of the multiple GSHP units for both of heating and cooling.

- The bypass system in the primary side of the HR-GSHP system is controlled to maximize the direct heat recovery effect when GSHP units are simultaneously providing both of heating and cooling.

2) The operation of HR-GSHP system with the control system could be verified by using the field test apparatus. Therefore, the HR-GSHP system with the developed control system can drastically reduce the total length of GHEXs according to the heating and cooling supply and the initial cost although the initial investment cost is generated.

\section{ACKNOWLEDGMENTS}

This study is based on results obtained from the project "Renewable energy heat utilization technology development," commissioned by the Japan national agency New Energy and Industrial Technology Development Organization (NEDO).

\section{NOMENCLATURE}

$\mathrm{c}_{\mathrm{p}}=$ Specific heat at constant pressure $[\mathrm{kJ} / \mathrm{kg} / \mathrm{K}]$

$\mathrm{E}=$ Electric power consumption $[\mathrm{kW}]$

$\mathrm{G}=$ Flow rate $\left[\mathrm{m}^{3} / \mathrm{s}\right]$

$\mathrm{L}=$ Length $[\mathrm{m}]$

$\mathrm{Q}=$ Heat load, heat extraction $[\mathrm{kW}]$

q' = Heat extraction rate per length and temperature difference $[\mathrm{W} / \mathrm{m} / \mathrm{K}]$

$\mathrm{T}=$ Temperature $\left[{ }^{\circ} \mathrm{C}\right]$

$\varrho=$ Density $\left[\mathrm{kg} / \mathrm{m}^{3}\right]$

\section{Subscripts}

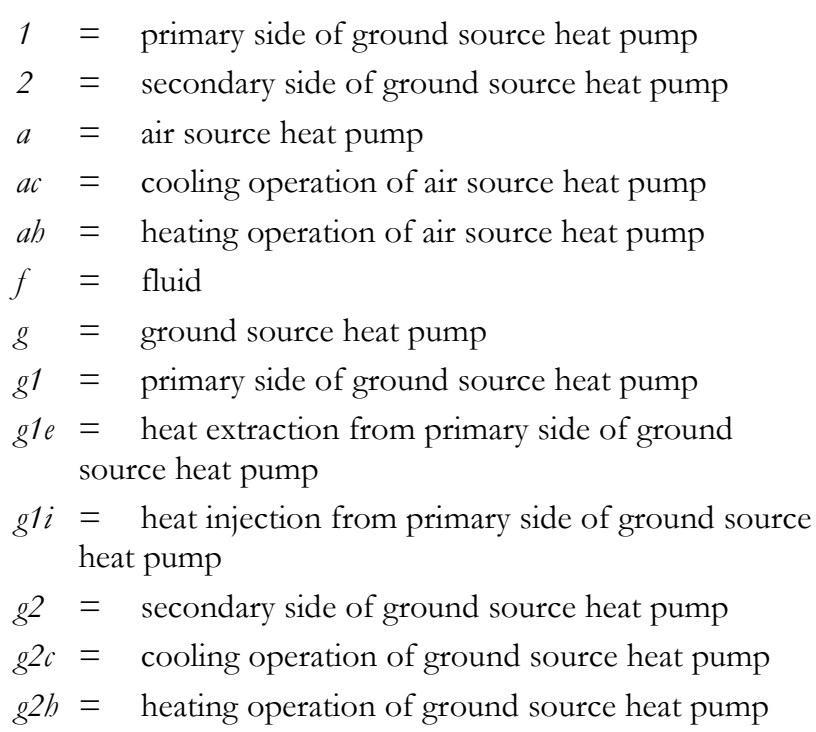

$1=$ primary side of ground source heat pump

$2=$ secondary side of ground source heat pump

$a=$ air source heat pump

$a c=$ cooling operation of air source heat pump

$a b=$ heating operation of air source heat pump

$f=$ fluid

$g \quad=$ ground source heat pump

g1 $=$ primary side of ground source heat pump

source heat pump

heat pump

g2 $=$ secondary side of ground source heat pump

$g 2 h=$ heating operation of ground source heat pump

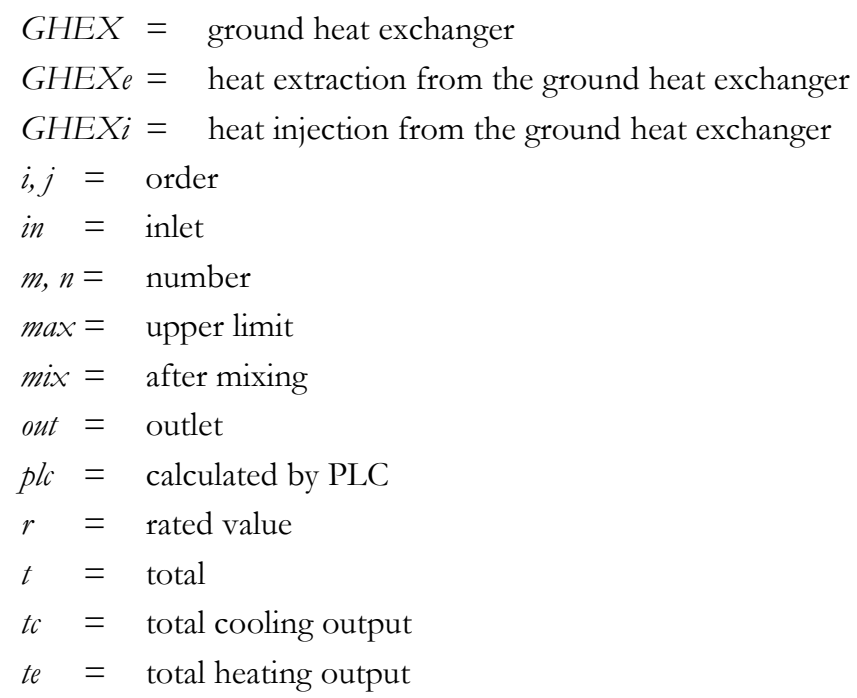




\section{REFERENCES}

ASHRAE. 2008, ASHRAE handbook 2008 HVAC Systems and Equipment. Chapter 8, 8.10

Edwards. K. C, D. P. Finn: Generalised water flow rate control strategy for optimal part load operation of ground source heat pump systems, Applied Energy, 150, pp. 50-60, 2015

Gao. J, G. Huang, X. Xu: Space temperature control of a GSHP-integrated air-conditioning system, Energy and Buildings, pp.127-136, 2015

Katsura. T, Y. Nakamura, K. Nagano: Development of a computer aided simulation program for the ground source heat pump system combined cooling tower and its application, Proceedings of 10th IEA Heat Pump Conference, Tokyo, 2011-5

Katsura. T, Y. Nakamura, K. Nagano: Experimental proof of seasonal performance of the ground source heat pump system applying variable water flow control and multi-split system, Proceedings of 10th IEA Heat Pump Conference, Tokyo, 2011-5

Katsura. T, Y. Nakamura, M. Hirata, Y. Matsuo : Performance Analysis and Operation Improvement of the Hybrid Ground Source Heat Pump System by Using Performance Prediction Tool, Proceedings of 11th IEA Heat Pump Conference 2014, Montoreal, 2014-5

Katsura. T, K. Nagano, Y. Nakamura : Investigation of a Design and Operation Method for a Heat Recovery Ground Source Heat Pump System, Proceedings of ASHRAE annual conference, Conference Paper, Long Beach, 2017-6 